\title{
Anorectal incontinence and rectal prolapse: differential assessment of the innervation to puborectalis and external anal sphincter muscles
}

\author{
S J SNOOKS, M M HENRY, AND M SWASH \\ From the Department of Physiology, St Mark's Hospital, London.
}

SUMMARY The innervation of the puborectalis and external anal sphincter muscles was studied in 32 patients with idiopathic (neurogenic) faecal incontinence, 12 of whom also had complete rectal prolapse, using transcutaneous spinal stimulation, transrectal pudendal nerve stimulation, single fibre EMG, anorectal manometry, and measurement of perineal descent. Fourteen normal subjects served as controls. Significant increases in the spinal motor latencies from L1 to the puborectalis and external anal sphincter muscles were shown in all 32 incontinent patients $(p<0.01)$. The single fibre (EMG) fibre density was increased in the puborectalis muscle in $60 \%$ and in the external anal sphincter in $75 \%$ of patients. An increased pudendal nerve terminal motor latency was found in $68 \%$ of patients; $69 \%$ had an abnormal degree of perineal descent and all had reduced anal canal contraction pressures. These data show that the different innervations of the puborectalis and external anal sphincter muscles are both damaged in patients with anorectal incontinence.

There is histological ${ }^{1}$ and electromyographic $(\mathrm{EMG})^{2}{ }^{3}$ evidence of damage to the innervation of the external anal sphincter in patients with idiopathic faecal incontinence. We have recently shown that the pudendal nerve terminal motor latency ${ }^{4}$ is increased in these incontinent patients, but that nerve conduction in the sacral roots is normal, suggesting a distal lesion in the nerve supply to the external anal sphincter muscle. ${ }^{45} \mathrm{We}$ have suggested that this distal innervation could be because of stretch injury to the pudendal nerves during perineal descent, injury sustained during childbirth, to nerve entrapment in the pelvis or a combination of these factors. ${ }^{1467}$

The anorectal angulation maintained by the pull of the muscular sling formed by the puborectalis muscle, however, is considered to be more important in the maintenance of continence than the action of the external and sphincter muscle..$^{8-10}$ Indeed, in our initial histopathological studies ${ }^{1}$ we found that the puborectalis muscle was more severely damaged than the external anal sphincter muscle. ${ }^{1711}$ The pathogenesis of denervation of

Address for correspondence Mr S J Snooks, St Mark’s Hospital, City Road. London ECIV 2PS

Received for publication 27 June 1984 this muscle in anorectal incontinence must therefore also be considered.

The innervation of the puborectalis muscle is controversial. Electrical stimulation of the pelvic motor nerves causes contraction of the puborectalis but not of the external anal sphincter, ${ }^{12}$ suggesting that the puborectalis is supplied by the pelvic nerves, ${ }^{12}$ and the external anal sphincter by the pudendal nerves. ${ }^{13}$ Both the pudendal nerves and the pelvic motor nerves arise from the S3 and S4 spinal segments. ${ }^{14}$ In this paper we present electrophysiological evidence of damage to the separate innervations of the puborectalis and external anal sphincter muscles in anorectal incontinence.

\section{Methods}

\section{PATIENTS}

Two groups of patients were studied, one with faecal incontinence alone (group I) and the other with faecal incontinence and complete rectal prolapse (group II). None had urinary incontinence. Group I consisted of 20 women aged 38-73 years (mean 59 years) and group II, 12 women aged $22-80$ years (mean 55 years). Patients with sphincter damage caused by anorectal surgery 
or childbirth injury were excluded, as were diabetic patients and patients suffering from other neurological diseases.

Fourteen women aged 38-70 years (mean 49 years) attending for follow up after treatment of colonic polyps or other minor anorectal conditions, all with a normal defaecatory pattern, served as controls for the measurement of spinal latency, pudendal nerve terminal motor latency, anorectal manometry and perineal descent.

\section{GROUP I: IDIOPATHIC FAECAL INCONTINENCE}

(Table 1)

Fourteen of these 20 patients were incontinent of solid stool and six of liquid stool. The mean duration of incontinence was 6.9 years (range 0.5-15 years). Seven patients reported a difficult childbirth and five patients gave a history of excessive defaecation straining (Table 1).

On examination all 20 patients had a lax or patulous anus and the anal reflexes were absent. Twelve patients had perineal descent. ${ }^{6}$

\section{GROUP II: IDIOPATHIC FAECAL INCONTINENCE} AND RECTAL PROLAPSE (Table 2)

Nine of these 12 patients were incontinent of solid stool and three of liquid stool. The mean duration of incontinence was five years (range $0 \cdot 5-13$ years). All 12 patients had complete rectal prolapse. Four patients reported a difficult childbirth and eight patients gave a history of excessive defaecation straining (Table 2).
On examination all 12 patients had a lax or patulous anus with complete rectal prolapse on straining and absence of the anal reflex. Perineal descent, ${ }^{6}$ was a feature in 10 patients.

\section{Methods}

\section{ANORECTAL MANOMETRY}

Anal pressures at rest and during maximal voluntary contraction were measured in the sphincter zone using standard techniques developed at $\mathrm{St}$ Mark's Hospital. ${ }^{2}$

\section{SINGLE FIBRE ELECTROMYOGRAPHY (EMG) External anal sphincter muscle}

Single fibre EMG of the external anal sphincter was carried out using the method previously described from this laboratory. ${ }^{2} 3$ Standard single fibre EMG electrodes and EMG apparatus were used.

\section{Puborectalis muscle}

The puborectalis muscle was approached from a point $1.5 \mathrm{~cm}$ posterior to the anal verge, angling the electrode anteriorly in the midline so as to enter the puborectalis muscle. Correct placement of the electrode was confirmed by digital examination of the rectum. Single muscle fibre action potentials were recorded when the electrode tip was at least $2 \mathrm{~cm}$ beneath the surface of the skin, the external anal sphincter muscle being more superficially situated. The fibre density,

Table 1 Group I: Idiopathic faecal incontinence: clinical features

\begin{tabular}{|c|c|c|c|c|c|}
\hline Case (no) & Age (y) & Duration FI (y) & History of defaecation straining & Parity & Obstetric history \\
\hline 1 & 38 & 4 & - & 0 & - \\
\hline 2 & 40 & 9 & - & 1 & Forceps + PSL \\
\hline 3 & 41 & 1.5 & - & 2 & Forceps+breech \\
\hline 4 & 43 & 2 & - & 2 & PSL \\
\hline 5 & 49 & 15 & - & 5 & 2 PSL \\
\hline 6 & 50 & 2 & + & 2 & - \\
\hline 7 & 52 & 0.5 & + & 4 & Caesarian section + PSL \\
\hline 8 & 53 & 5 & - & 0 & - \\
\hline 9 & 55 & 0.5 & + & 2 & - \\
\hline 10 & 61 & 0.75 & - & 3 & - \\
\hline 11 & 62 & 2 & - & 2 & - \\
\hline 12 & 62 & 4 & - & 2 & - \\
\hline 13 & 65 & 10 & + & 2 & - \\
\hline 14 & 68 & $1 \cdot 5$ & - & 2 & - \\
\hline 15 & 70 & 0.5 & - & 0 & - \\
\hline 16 & 70 & 1 & + & 4 & - \\
\hline 17 & 71 & 3 & - & 1 & - \\
\hline 18 & 73 & $0 \cdot 5$ & - & 0 & - \\
\hline 19 & 73 & 5 & - & 2 & Forceps \\
\hline 20 & 75 & 5 & - & 2 & Forceps \\
\hline
\end{tabular}

PSL: Prolonged second stage of labour, FI: Faecal incontinence. 
Table 2 Group II: Idiopathic faecal incontinence and rectal prolapse: clinical features

\begin{tabular}{|c|c|c|c|c|c|}
\hline Case (no) & Age (y) & Duration FI (y) & Defaecation straining & Parity & Obstetric history \\
\hline 21 & 22 & 0.5 & - & 2 & - \\
\hline 22 & 36 & 5 & + & 4 & - \\
\hline 23 & 40 & 9 & + & 1 & Caesarian section \\
\hline 24 & 43 & 1 & - & 1 & Breech \\
\hline 25 & 44 & 3 & + & 0 & - \\
\hline 26 & 54 & $0 \cdot 5$ & - & 0 & - \\
\hline 27 & 63 & $1 \cdot 5$ & + & 2 & Forceps \\
\hline 28 & 64 & 5 & + & 2 & - \\
\hline 29 & 64 & 13 & + & 1 & Forceps + PSL \\
\hline 30 & 73 & 16 & + & 0 & - \\
\hline 31 & 75 & 6 & + & 0 & - \\
\hline 32 & 80 & 8 & - & 0 & - \\
\hline
\end{tabular}

PSL: Prolonged second stage of labour, FI: Faecal incontinence.

which is defined as the mean number of muscle fibres innervated by a single motor unit recorded within the uptake of the electrode, was calculated by taking the mean number of muscle action potentials in 20 consecutive recordings at different sites within these muscles. ${ }^{2} 3$

\section{TRANSCUTANEOUS SPINAL STIMULATION}

Transcutaneous spinal stimulation ${ }^{15}$ was achieved using the method we have previously described. ${ }^{5}$ The patient was placed in the left lateral position and a ground electrode was connected from the right upper thigh to the pre-amplifier of the EMG. A single impulse of $800-2000$ volts, decaying with a time constant of $50 \mu \mathrm{sec}$, was delivered through two saline soaked packs with the cathode firmly held over the spinous process of the first lumbar vertebra and the anode cranially. The sites of nerve stimulation and recording used are shown diagramatically in Figure 1.

EXTERNAL ANAL SPHINCTER RESPONSE

The response in the external anal sphincter muscle (Fig. 2) was recorded though two holes of a $3 \mathrm{~cm}$ long, three pole telephone jack plug-electode lubricated with electrode jelly, situated in the anal canal. The third pole of the electrode was connected to ground. The onset of the stimulus triggered the oscilloscope of the EMG machine, and the latency of the ended response in the external anal sphincter was measured on the paper print out (Fig. 2).

\section{PUBORECTALIS RESPONSE}

The latency of the response in the puborectalis muscle (Fig. 2) after spinal stimulation was recorded using a pair of $1 \mathrm{~cm}$ diameter steel electrode plates mounted $1 \mathrm{~cm}$ apart on the tip of a finger stall. The latter could thus be held by the examiner's finger in contact with the puborectalis muscle bar on the posterior wall of the anorectal angulation. The spinal stimulus parameters were the same as those described above. In preliminary studies the origin of this intra-anal surfacerecorded response from the puborectalis muscle was verified by recordings using a needle electrode inserted into the muscle percutaneously.

DIGITALLY-DIRECTED PUDENDAL NERVE TERMINAL MOTOR LATENCY MEASUREMENT This method which has been described elsewhere ${ }^{4} 5$

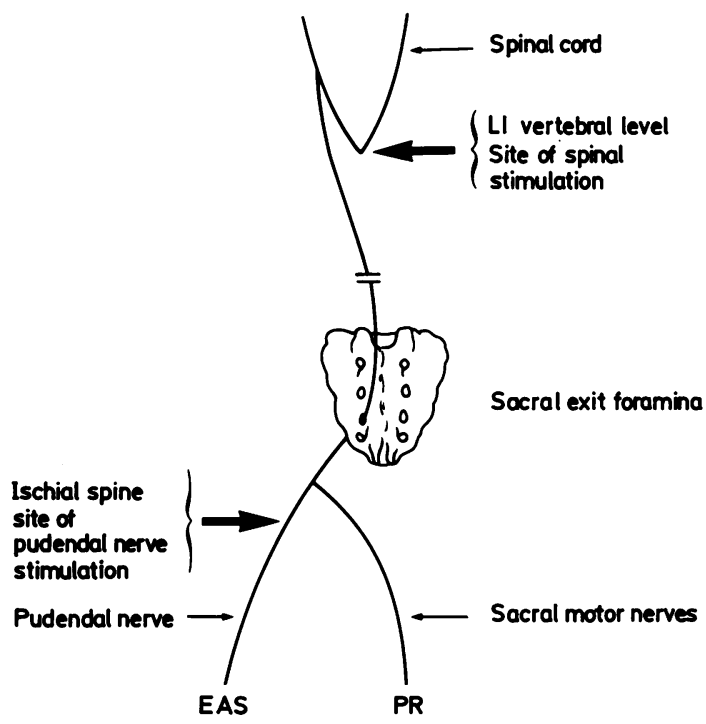

Fig. 1 Sites of stimulation; conus medullaris (spinal stimulation) and ischial spines (transrectal pudendal nerve stimulation). EAS=external anal sphincter and $P R=$ puborectalis. 


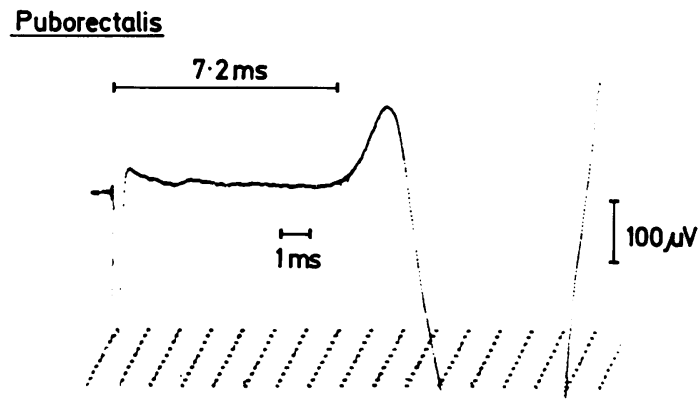

External anal sphincter
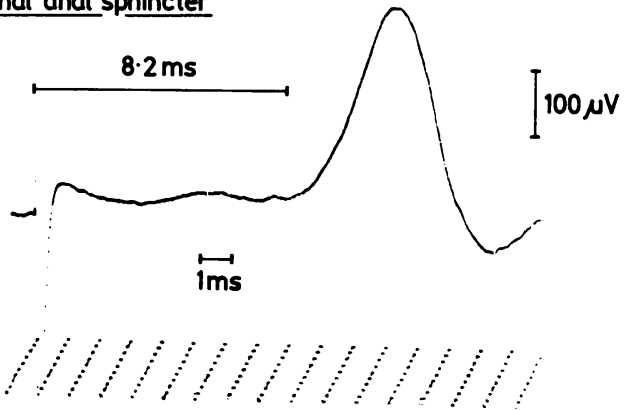

Fig. 2 Recordings of the latencies of the responses in the puborectalis and external anal sphincter muscles following transcutaneous spinal stimulation at L1. Both are increased (see text).

was developed at St Mark's from the technique of electroejaculation described by Brindley for use in patients with impotence caused by paraplegia. ${ }^{16}$ The stimulatory device consists of a rubber finger stall having two metal stimulating electrodes at its tip, and two metal $1 \mathrm{~cm}$ diameter recording electrode discs mounted $3 \mathrm{~cm}$ proximally at the base of the finger. ${ }^{4}$ The latter pick up the muscle action potential during external and sphincter contraction occurring in response to the electrical stimulus. Stimulation of the pudendal nerves on either side was achieved using square wall supramaximal stimuli of 50 volts and $0 \cdot 1 \mathrm{~ms}$ duration (Fig. 1). Two recordings of five consecutive traces at $1 \mathrm{~ms}$ intervals were made on each side of the pelvis. The latency of the response was measured on the paper print out.

\section{MEASUREMENT OF PERINEAL POSITION AND}

DESCENT

Perineal descent is recognised clinically by ballooning of the perineum during a straining effort. Measurements of this were made using a graduated latex cylinder held against the anal verge and moving within a steel frame pressed against the ischial tuberosities. ${ }^{6}$ Measurements were taken of the position of the perineum in relation to the ischial tuberosities, both at rest and during a maximal straining effort (Fig. 3).

\section{Results}

\section{GROUP I: IDIOPATHIC FAECAL INCONTINENCE}

(Table 3)

There were significant differences in this group of patients from the control subjects in resting and voluntary contraction anal canal pressures, single fibre EMG fibre density of the external anal sphincter and puborectalis muscles, spinal motor latencies from $\mathrm{L} 1$ to both muscles, mean pudendal nerve terminal motor latency and the position of the perineum at rest and on straining in relation to the plane of the ischial tuberosities (Fig. 3).

A statistical study of the fibre density in the human puborectalis muscle is not yet available and in this investigation fibre densities in the muscle were not studied in the control patients. In single fibre EMG recordings in human limb muscles the fibre density is normally less than 1.6 except in aged subjects. ${ }^{11718}$ In the external anal sphincter muscle the fibre density in normal subjects is $1 \cdot 5 \pm 0 \cdot 16(\mathrm{SD}){ }^{2}$

There were no significant differences between the fibre densities and between the spinal motor latencies from $\mathrm{L} 1$ in recordings from external anal sphincter and puborectalis muscles in group I patients.

Table 3 Results

\begin{tabular}{|c|c|c|c|}
\hline & Group I & Group II & Normals \\
\hline \multicolumn{4}{|l|}{$\begin{array}{l}\text { Anorectal manometry } \\
\text { (cm of water) }\end{array}$} \\
\hline Resting pressure & $33 \cdot 6(18 \cdot 7)^{*}$ & ${ }^{*} 35.9(22.6)^{*}$ & $* 80 \cdot 6(23 \cdot 8)$ \\
\hline Voluntary contraction & $47 \cdot 8(38 \cdot 7)^{*}$ & ${ }^{*} 42.9(25.4)^{*}$ & ${ }^{*} 120 \cdot 0(30 \cdot 8)$ \\
\hline \multicolumn{4}{|l|}{ Single fibre EMG } \\
\hline Fibre density & & & \\
\hline External anal sphincter & $1.9(0 \cdot 22)^{*}$ & * $1.9(0.22)^{*}$ & * $1.5(0 \cdot 16)$ \\
\hline $\begin{array}{l}\text { Puborectalis } \\
\text { L1 Spinal latency (ms) }\end{array}$ & $1.9(0 \cdot 4)^{*}$ & $1 \cdot 7(0 \cdot 22)^{*}$ & * $1.5(0 \cdot 16)$ \\
\hline External anal sphincter & $7 \cdot 5(1.4)^{*}$ & $7 \cdot 1(1 \cdot 3)^{*}$ & $5 \cdot 6(0 \cdot 4)$ \\
\hline $\begin{array}{l}\text { Puborectalis } \\
\text { Mean pudendal nerve }\end{array}$ & $8 \cdot 0(1.4)^{*}$ & $8 \cdot 6(3 \cdot 1)^{*}$ & $4 \cdot 7(0 \cdot 4)$ \\
\hline Terminal motor latency (ms) & $2 \cdot 6(0 \cdot 5)^{*}$ & $2 \cdot 8(0 \cdot 5)^{*}$ & $1.9(0 \cdot 2)$ \\
\hline Perineal descent $(\mathrm{cm})$ & & & \\
\hline Rest & $+0.7(0.4)^{*}$ & $+0.9(0.5)^{*}$ & $+2 \cdot 5(0 \cdot 6)$ \\
\hline Straining & $-1 \cdot 4(0 \cdot 7)^{*}$ & $-1 \cdot 6(0 \cdot 6)^{*}$ & $+0.9(1.0)$ \\
\hline
\end{tabular}

(+) denotes distance above the plane of the ischial tuberosities $(-)$ denotes distance below the plane of the ischial tuberosities Figures in brackets denote standard deviations

* significant difference from normals $(p<0 \cdot 01)$ Wilcoxon's rank sum test 


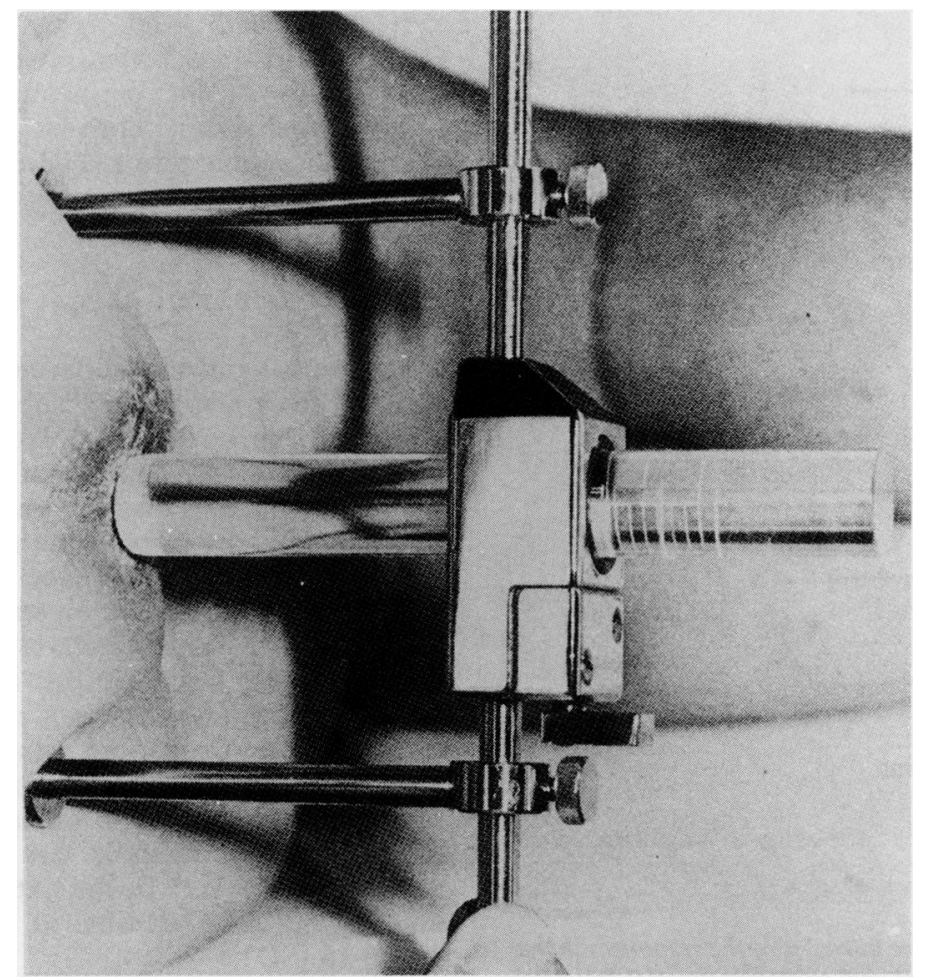

Fig. 3 Measuring the degree of perineal descent in a patient with faecal incontinence.

GROUP II: IDIOPATHIC FAECAL INCONTINENCE AND RECTAL PROLAPSE (Table 3)

The findings in this group of patients were the same as those in group I. There were no significant differences between any of the variables studied in patients in groups I and II. Histograms of both groups' spinal latencies are shown in Figure 4.

\section{CONTROL SUBJECTS}

Data from the normal subjects are shown in Table 3.

\section{Discussion}

We have developed the techniques of transcutaneous spinal stimulation and digitally directed pudendal nerve stimulation in order to directly assess nerve conduction in the innervations of the puborectalis and external and sphincter muscles. ${ }^{4519}$ Transcutaneous spinal stimulation evaluates nerve conduction to the muscles from the site of spinal root stimulation at the $\mathrm{L} 1$ vertebral level. ${ }^{6}$ Pudendal nerve stimulation tests conduction in the distal portion of the pudendal nerves innervating the external anal sphincter muscle. ${ }^{419}$
The single fibre EMG fibre density is a measure of the packing density of muscle fibres innervated by a single motor unit. ${ }^{23}{ }^{17} \mathrm{~A}$ raised fibre density in the context of this finding is consistent with reinnervation within a muscle due to collateral axonal sprouting. ${ }^{2} 71718$ An increased fibre density after reinnervation in skeletal muscle - for example, in poliomyelitis, is a persistent phenomenon, because axon sprouting causes a permanent anatomical change in motor unit distribution within the muscle.

The extent of reinnervation as shown by the single fibre EMG fibre density was similar in the puborectalis and external anal sphincter muscles in groups I and II (Table 3), suggesting that rectal prolapse in the latter patients was because of weakness of the pelvic floor muscles secondary to damage to the nerve supply of these muscles, as described by Neill et al. ${ }^{3}$ Butler $^{20}$ observed rectal prolapse and incontinence of this type in patients with cauda equina lesions and similar observations have been made after excision of the sacrum. ${ }^{21}$ Rectal prolapse occurring without faecal incontinence probably has a different pathogenesis. ${ }^{3}$

The suggestion made by Percy et $a^{12}$ that the 


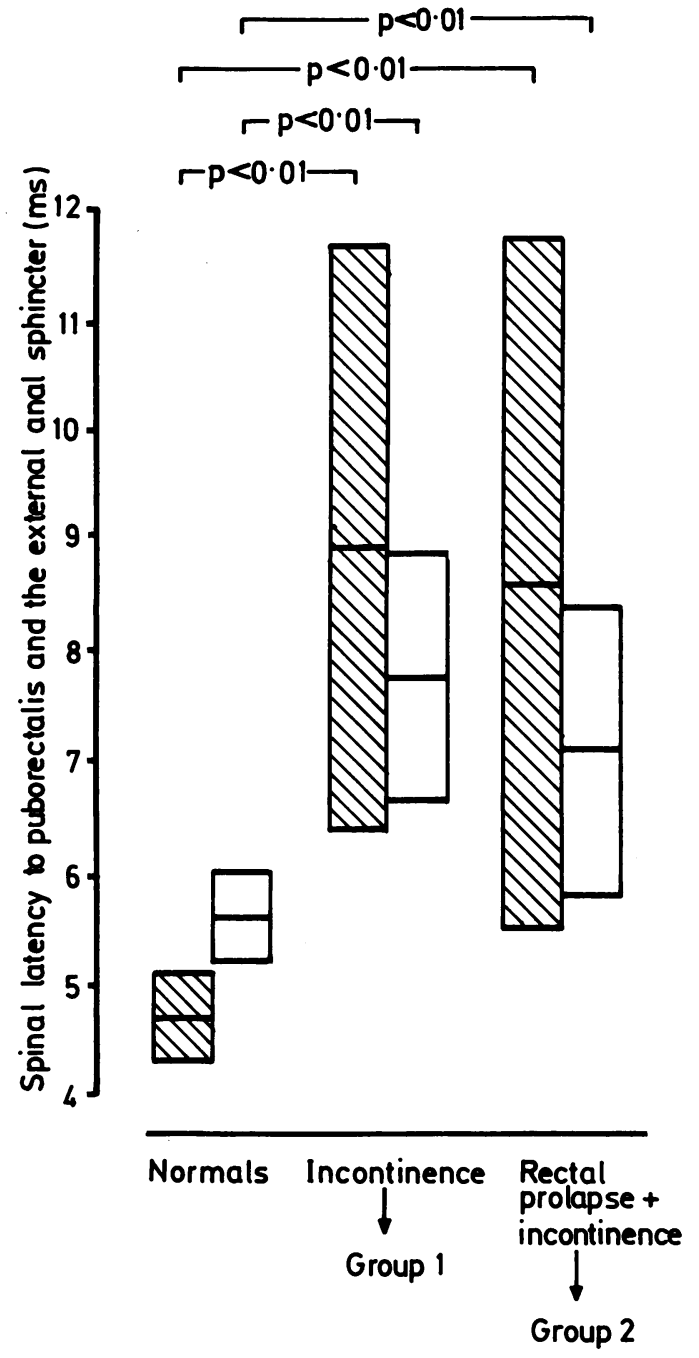

that the conduction velocity in the pudendal nerve was approximately 50 metres per second; a difference in latency of $1 \mathrm{~ms}$ thus implies a difference in nerve length of about $5 \mathrm{~cm}$. The innervation of the puborectalis and external anal sphincter muscles must therefore be considered separately.

The finding of an increased spinal latency to the puborectalis muscle provides direct evidence of damage to the nerve supply of this muscle. The correlation coefficient between the spinal latencies to the puborectalis and external anal sphincter muscles in normal subjects was $0 \cdot 81$ (Fig. 5). This correlation was reduced in both groups of patients $(0.63$ in group II and 0.76 in group I), a finding consistent with damage of varying degrees to the innervations of these muscles in both groups of patients. Twenty two $(69 \%)$ patients had an increased pudendal nerve terminal motor latency (14 in group I and eight in group II); evidence of damage to the terminal portion of the pudendal nerves in these patients. Our data therefore suggest that, in idiopathic incontinence, both the pudendal nerves innervating the external anal sphincter, and the sacral motor nerves derived from the S3 and S4 roots innervating the puborectalis muscle are damaged (Fig. 5). This was related to excessive defaecation straining (45\% of patients) and to an abnormal degree of perineal descent $(69 \%$ of patients), factors that we have shown to be

Fig. 4 Mean spinal latencies to puborectalis and the external anal sphincter muscles $\square$, represented as one standard deviation either side of the mean, in normal subjects, patients with incontinence (group I) and patients with incontinence and rectal prolapse (group II). The significance of the results in groups I and II compared with normal subjects is indicated (Wilcoxons's rank sum test),

puborectalis and external anal sphincter muscles received a different innervation is supported by the data in our control subjects. In these subjects different spinal latencies were recorded to these muscles. The mean difference between these two latencies $(1 \mathrm{~ms})$ was greater than expected from the anatomical position of the two muscles, a distance of about $1 \mathrm{~cm}$. Kiff and $\mathrm{Swash}^{4}$ showed

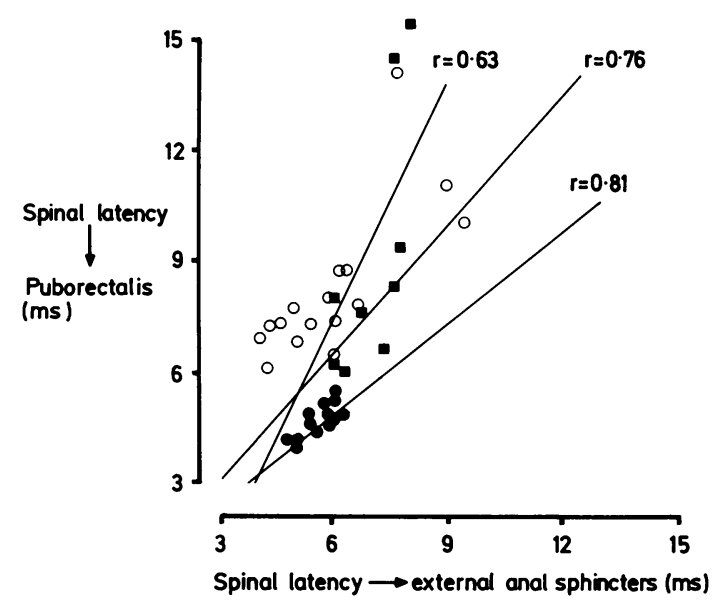

Fig. 5 Spinal latencies recorded after stimulation at L1 in puborectalis and external anal sphincter muscles in normal subjects $(\mathbf{O} ; r=0.81)$, patients with faecal incontinence ( $\square$; $r=0.76)$, and patients with incontinence and rectal prolapse $(O ; r=0.63)$. There is less close correlation between the spinal latencies to the two muscles in the patients with incontinence, than in the normal subjects. 
associated with nerve damage, even without incontinence. $^{619}$

Slowing of conduction in a nerve may occur either because of diffuse disease within the nerve itself or from localised entrapment at a more proximal site. ${ }^{18}$ The increased distal motor latency in the pudendal innervation of the external anal sphincter muscle contributes partly to the increased spinal latency from L1 to this muscle because the pudendal nerves are probably damaged at an inaccessible site, more proximal than the level of the ischial spines. ${ }^{419}$

The methods we have used in this study allow a more detailed clinical assessment of these muscles and their nerve supply than has hitherto been possible, and thus make possible a more complete investigation of the role of defaecation straining and perineal descent in the development of pelvic floor disorders.

We thank the St Mark's Hospital Research Fund for financial support.

\section{References}

1 Parks AG, Swash M, Urich H. Sphincter denervation in anorectal incontinence and rectal prolapse. Gut 1977; 18: 656-65.

2 Neill ME, Swash M. Increased motor unit fibre density in the external anal sphincter muscle in anorectal incontinence: a single fibre EMG study. $J$ Neurol Neurosurg Psychiatry 1980; 43: 343-7.

3 Neill ME, Parks AG, Swash M. Physiological studies of the pelvic floor in idiopathic faecal incontinence and rectal prolapse. Br J Surg 1981; 68: 531-6.

4 Kiff E, Swash M. Slowed conduction in the pudendal nerves in idiopathic (neurogenic) faecal incontinence. Br J Surg 1984; 71: 614-6.

5 Kiff E, Swash M. Normal proximal and delayed distal conduction in the pudendal nerves of patients with idiopathic (neurogenic) faecal incontinence. $J$ Neurol Neurosurg Psychiatry 1984; 47: 820-3.

6 Henry MM, Parks AG, Swash M. The pelvic floor musculature in the descending perineum syndrome. Br J Surg 1982; 69: 470-2.

7 Swash M. The neuropathology of idiopathic faecal incontinence. In: Smith WT, Cavanagh JB, eds. Recent advances in Neuropathology. Edinburgh: Churchill Livingstone, 1982; 2.

8 Parks AG, Porter NH, Melzack J. Experimental study of the reflex mechanism controlling the muscles of the pelvic floor. Dis Colon Rectum 1962; 5: 407-14.

9 Parks AG, Porter NH, Hardcastle J. The syndrome of the descending perineum. Proc Roy Soc Med 1966; 59: 477-82.

10 Parks AG. Anorectal incontinence. Proc Roy Soc Med 1975; 68: 681-90.

11 Beersiek F, Parks AG, Swash M. Pathogenesis of anorectal incontinence: a histometric study of the anal sphincter musculature. J Neurol Sci 1979; 42: 111-27.

12 Percy J P, Neill ME, Swash M, Parks AG. Electrophysiological study of motor nerve supply of the pelvic floor. Lancet 1981; 1: 16-7.

13 Wunderlich $M$, Swash $M$. The overlapping innervation of the two sides of the external anal sphincter by the pudendal nerves. J Neurol Sci 1983; 59: 97-109.

14 Sherrington CS. Notes on the arrangement of some motor fibres in the lumbosacral plexus. J Physiol (Lond) 1892; 13: 672-5.

15 Merton PA, Moreton HB, Hill DK, Marsden CD. Scope of a technique for electrical stimulation of human brain, spinal cord and muscle. Lancet 1982; 9: 597-600.

16 Brindley GS. Electroejaculation: its technique, neurological implications and uses. J Neurol Neurosurg, Psychiatry 1981; 44: 9-18.

17 Stalberg E, Trontelj JV. Single fibre electromyography. Old Woking, Surrey, UK: The Mirvalle Press Ltd, 1979.

18 Swash M, Schwartz MS. Neuromuscular diseases: a practical approach to diagnosis and management. Berlin, Heidelsey, New York: Springer-Verlag 1981.

19 Kiff ES, Barnes PRH, Swash M. Evidence of pudendal neuropathy in patients with perineal descent and chronic straining at stool. Gut 1984; 24: 1279-82.

20 Butler ECB. Complete rectal prolapse following removal of tumours of the cauda equina. Proc Roy Soc Med 1965; 47: 521-2.

21 Gunterberg B, Kewenter J, Peterson L, Stener B. Anorectal function after major resections of the sacrum with bilateral or unilateral sacrifice of sacral nerves. Br J Surg 1976; 63: 546-54. 